PACS 62.20.fq

\title{
Low-temperature superplasticity of commercial sheets of the titanium alloy $\mathrm{Ti}-6 \mathrm{Al}-4 \mathrm{~V}$
}

\author{
R. M. Kashaev ${ }^{\dagger}$ R. Ya. Lutfullin, M. I. Nagimov \\ †rishat@kashaev.ru
}

Institute for Metals Superplasticity Problems, RAS, 39 Khalturin St., 450001, Ufa, Russia

\begin{abstract}
The paper presents the results of uniaxial tensile mechanical testing, at relatively low temperatures in the range of $650^{\circ} \mathrm{C}-$ $800^{\circ} \mathrm{C}$ and at strain rates ranging from $7 \times 10^{-4} \mathrm{~s}^{-1}$ to $4 \times 10^{-2} \mathrm{~s}^{-1}$, of the titanium alloy Ti-6Al-4V specimens cut out along and across the rolling direction of a sheet. Low-temperature superplasticity has been revealed in sheets of the titanium alloy Ti-6Al-4V manufactured by the domestic metallurgical industry. Within the acceptable scatter of experimental data, the sheets are isotropic in the longitudinal and transverse directions with respect to flow stress and ductility in the range of temperatures and strain rates under study.
\end{abstract}

Keywords: low-temperature superplasticity, commercial titanium alloy Ti-6Al-4V sheets, tensile mechanical testing.

\section{Introduction}

It is known [1-3] that commercial titanium sheets of the VT6 type (an analogue of Ti-6Al-4V) exhibit superplastic properties at relatively high temperatures of $900-950^{\circ} \mathrm{C}$ and at strain rates in the range of $1 \times 10^{-4} \mathrm{~s}^{-1}-1 \times 10^{-2} \mathrm{~s}^{-1}$. In case these conditions are fulfilled, it is possible to produce from sheet billets a wide nomenclature of products for aircraft applications, using the method of superplastic forming (SPF) $[4,5]$. At the same time, a serious problem persists, related to the lack of economic profitability of manufacture of the above-mentioned products due to the high labour intensity, aggravated by the low resistance of the expensive die tooling at a temperature of about $927^{\circ} \mathrm{C}[2]$. The problem of low profitability of the production process of sheet titanium structures by superplastic forming based on conventional SP, at temperatures in the range of $900-950^{\circ} \mathrm{C}$, is universal and, due to the economic factor, it hinders the manufacture of a wide range of titanium products, both for aircraft and general construction applications [3]. Many researchers believe that a drastic way to introduce SP into the manufacturing industry through creating economically attractive SPF technologies may be a decrease in the SP temperature of an alloy under processing [5-9]. For example, according to the authors of [6-8], decreasing the SP temperature to $760^{\circ} \mathrm{C}$ can make the SPF production process of titanium alloys really economically feasible.

In recent years, VSMPO-AVISMA Corporation started to produce sheets of the alloy Ti-6Al-4V with improved superplastic properties [7]. Any calculation connected with the development and optimization of SPF, including the application of the numerical methods of mathematical modelling, should be based on certain information about the material. As a rule, such information represents constants included in the material constitutive relation, which are obtained from tensile tests. However, in scientific and technical literature there are no factual data on the exhibition of the superplasticity effect in commercial sheets at lower temperatures, in a temperature range starting from $750^{\circ} \mathrm{C}$ and lower, which hampers the development of real technologies by numerical methods.

The current study aims to investigate the superplastic properties of commercial sheets with a thickness of $1.0 \mathrm{~mm}$ and $1.5 \mathrm{~mm}$, made of the titanium alloy Ti-6Al-4V, in uniaxial tension in the region of lower temperatures and indentify the temperature range of possible exhibition of low-temperature SP in the materials under study.

\section{Experimental procedure}

In this study, Ti-6Al-4V alloy sheets with a thickness of 1.0 and $1.5 \mathrm{~mm}$ with improved superplastic properties, produced by VSMPO-AVISMA Corporation, were used. The chemical composition (wt\%) of the present alloy (the sheet with a thickness of $1.0 \mathrm{~mm}$ ) was $6.08-6.09 \mathrm{Al}$, 4.26-4.27 V, 0.21-0.25 Fe, $0.005 \mathrm{C}, 0.138-0.146 \mathrm{O}$, $0.003-0.006 \mathrm{~N}, 0.0006-0.0008 \mathrm{H}$, and the balance was Ti. The mechanical properties of the sheet with a thickness of $1.0 \mathrm{~mm}$ are: yield stress $\left(\sigma_{0.2}\right) 1044-1064 \mathrm{MPa}$, ultimate tensile strength 1105-1122 MPa, tensile elongation 9.1$9.9 \%$. Figure 1 shows a microstructure image of the sheet with a thickness of $1.0 \mathrm{~mm}$, taken in a transmission electron microscope JEM - 2000 EX. The alloy has an average grain size of $1.1 \mu \mathrm{m}$ determined by the linear intercept method. Uniaxial high-temperature tensile tests were performed on an INSTRON 1185 machine at $650^{\circ} \mathrm{C}, 700^{\circ} \mathrm{C}, 750^{\circ} \mathrm{C}$ and $800^{\circ} \mathrm{C}$ with deformation speeds of $0.5 \mathrm{~mm} / \mathrm{min}$, 


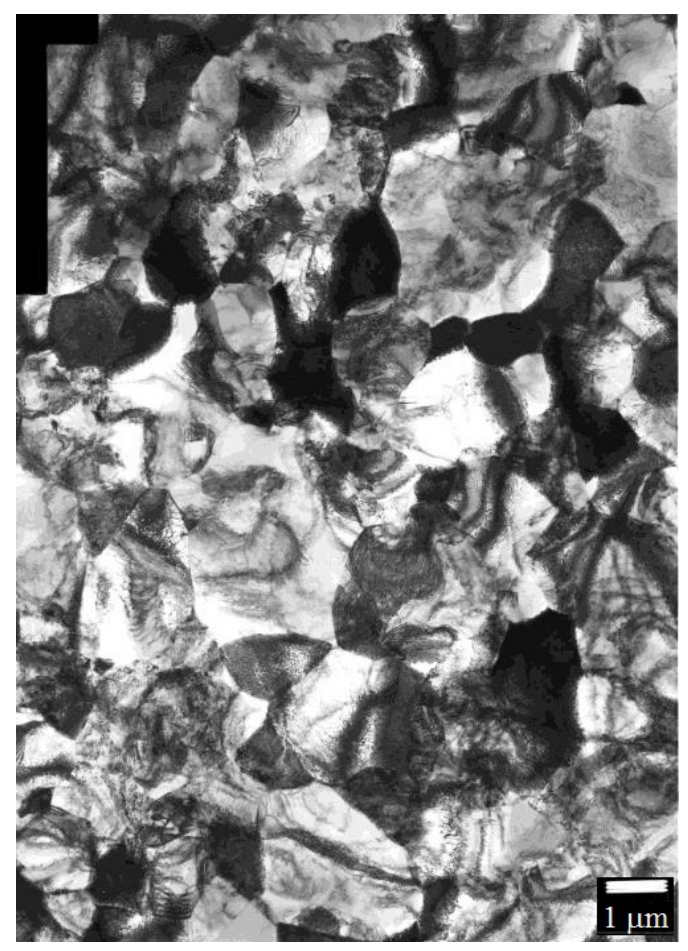

Fig. 1. Microstructure of the sheet with a thickness of $1.0 \mathrm{~mm}$.

$5.0 \mathrm{~mm} / \mathrm{min}$ and $50 \mathrm{~mm} / \mathrm{min}$, which approximately correspond to the initial strain rates of $4 \times 10^{-4} \mathrm{~s}^{-1}, 4 \times 10^{-3} \mathrm{~s}^{-1}$ and $4 \times 10^{-2} \mathrm{~s}^{-1}$.

The tensile specimens shown in Fig.2 were machined from the tensile axis being parallel (longitudinal) and perpendicular (transverse) to the rolling direction. The tests were made without a protective atmosphere. A total of 48 specimens were tested.

According to the test results, the elongation-to-failure of each specimen was determined by the formula:

$$
\delta=\left(L_{\mathrm{u}}-L_{\mathrm{o}}\right) / L_{\mathrm{o}}
$$

where $L_{\mathrm{o}}=20 \mathrm{~mm}$ is the original gauge length of a specimen; $L_{\mathrm{u}}$ is the final gauge length of a specimen.

The true flow stresses were determined by the formula:

$$
\sigma=\mathrm{P} / \mathrm{F}
$$

where $\mathrm{P}$ is the deformation resistance, $N ; F$ is the current cross-sectional area of the specimen, $\mathrm{mm}^{2}$, determined from the condition that the working part volume of a specimen is $F=\left(F_{\mathrm{o}} \times L_{\mathrm{o}}\right) / L$, where $F_{\mathrm{o}}$ is the initial cross-sectional area of a specimen, $L$ is the current length.

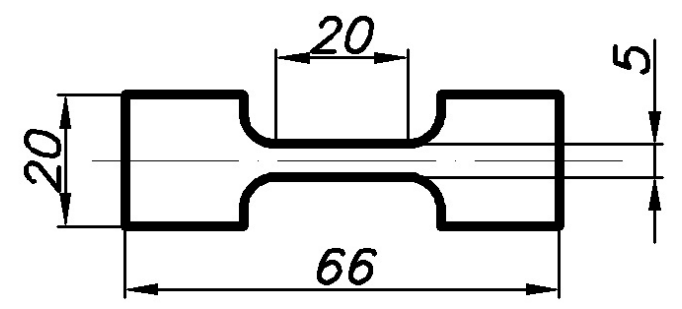

Fig. 2. Tensile test specimen.
One of the main characteristics of superplasticity is the coefficient $m$ expressing the sensitivity of the applied tension to the strain rate [7]. For each specimen, this coefficient was determined by multi-step switching of the deformation speed at the beginning of the test, according to the formula:

$$
m=\ln \left(P_{2} / P_{1}\right) / \ln \left(V_{1} / V_{1}\right)
$$

where $V_{1}$ and $V_{1}$ are the deformation speeds, before and after switching, $\mathrm{mm} / \mathrm{min} ; P_{1}$ and $P_{2}$ are the corresponding deformation forces, $N$.

\section{Results}

The effect of the deformation speed (strain rate) and temperature on the elongation to failure is shown in Fig.4-7.

These results show that the elongation of the sheet with a thickness of $1.0 \mathrm{~mm}$ is greater than the elongation of the sheet with a thickness of $1.5 \mathrm{~mm}$, and the direction of cutting of specimens (longitudinal or transverse) has no significant effect on elongation. The elongation of the sheet with a thickness of $1.5 \mathrm{~mm}$ grows with increasing temperature and decreasing deformation speed (strain rate) in the whole range of temperatures and strain rates under consideration. The elongation of the sheet with a thickness of $1.0 \mathrm{~mm}$ has the same behavior when tested at temperatures of 650 and $700^{\circ} \mathrm{C}$. The elongation reaches a maximum at temperatures of 750 and $800^{\circ} \mathrm{C}$ when the deformation speed is $5 \mathrm{~mm} / \mathrm{min}$. A further reduction in the speed to $0.5 \mathrm{~mm} / \mathrm{min}$ results in a decrease in elongation. This is likely due to the influence of the grain growth of alloy.

Figures 7 and 8 show the dependence of the flow stress and the strain-rate sensitivity coefficient $m$ on the strain rate in the sheet with a thickness of $1 \mathrm{~mm}$. The flow stress of the alloy increases with decreasing temperature and increasing strain rate. We see that the influence of the specimen's orientation on the flow stress is small and lies within the scatter of experimental data. Hence, the sheets are isotropic, which is a favorable property for superplastic forming. It is believed that a material exhibits superplastic properties if $m>0.3$ [6]. For a temperature of $650^{\circ} \mathrm{C}$ this condition is satisfied at a strain rate of $\xi<2 \times 10^{-3} \mathrm{~s}^{-1}$, for a temperature of $700^{\circ} \mathrm{C}-$ at $\xi<1 \times 10^{-2} \mathrm{~s}^{-1}$. At temperatures of $750^{\circ} \mathrm{C}$ and $800^{\circ} \mathrm{C}$ the material exhibits high-strain-rate superplasticity (see Fig.8).

The dependence of the flow stress and the coefficient $\mathrm{m}$ on the strain rate for the sheet with a thickness of $1.5 \mathrm{~mm}$ is similar to the behavior of the sheet with a thickness of 1.0 $\mathrm{mm}$. However, the flow stress of the sheet with a thickness of $1.5 \mathrm{~mm}$ is higher than that of the sheet with a thickness of 1.0 $\mathrm{mm}$, and the coefficient $\mathrm{m}$ is lower. The sheet with a thickness of $1.5 \mathrm{~mm}$ is isotropic, as well as the sheet with a thickness of $1.0 \mathrm{~mm}$. The sheet with a thickness of $1.5 \mathrm{~mm}$ starts to exhibit superplastic properties only when the temperature reaches $700^{\circ} \mathrm{C}$ at a strain rate of $\xi<2 \times 10^{-3} \mathrm{~s}^{-1}$.

\section{Conclusions}

1. The investigated sheets of the alloy Ti-6Al-4V exhibited 


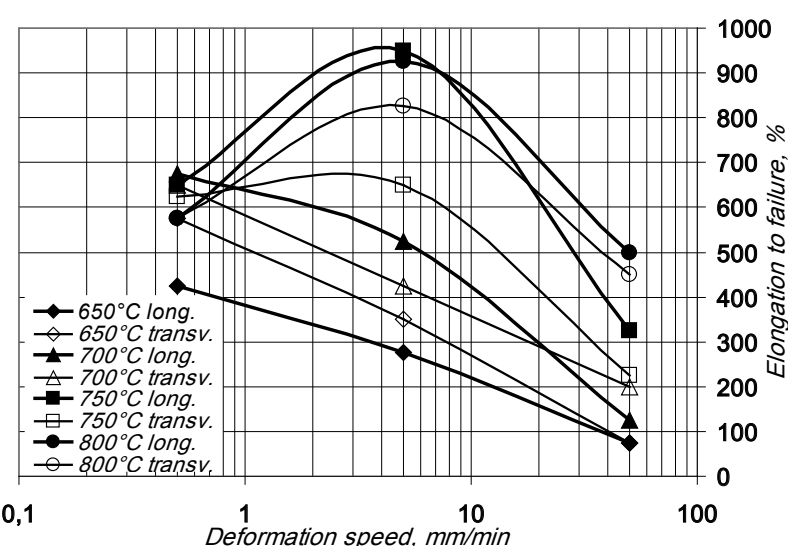

Fig. 3. Variation in the elongation-to-failure values of specimens, oriented parallel (longitudinal) and perpendicular (transverse) to the rolling direction of the sheet with a thickness of $1.0 \mathrm{~mm}$, as a function of deformation speed at different temperatures.

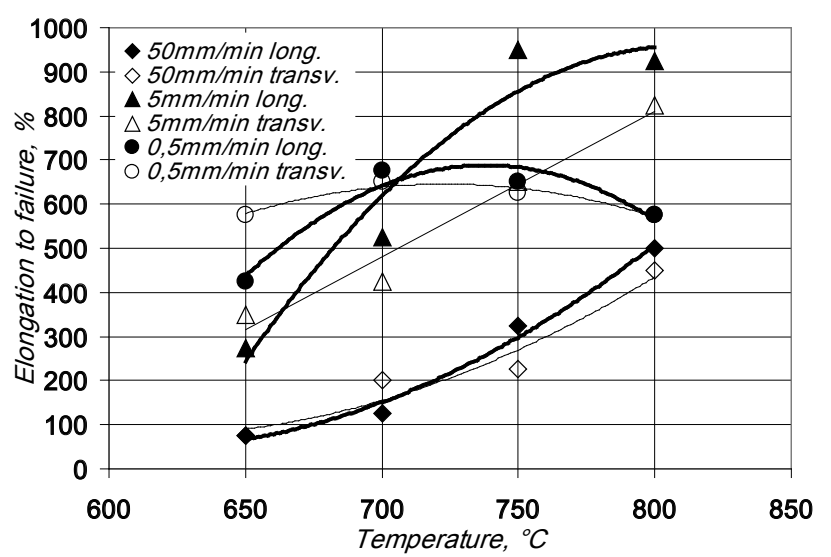

Fig. 5. Variation in the elongation-to-failure values of specimens, oriented parallel (longitudinal) and perpendicular (transverse) to the rolling direction of the sheet with a thickness of $1.0 \mathrm{~mm}$, as a function of temperature at different deformation speeds.

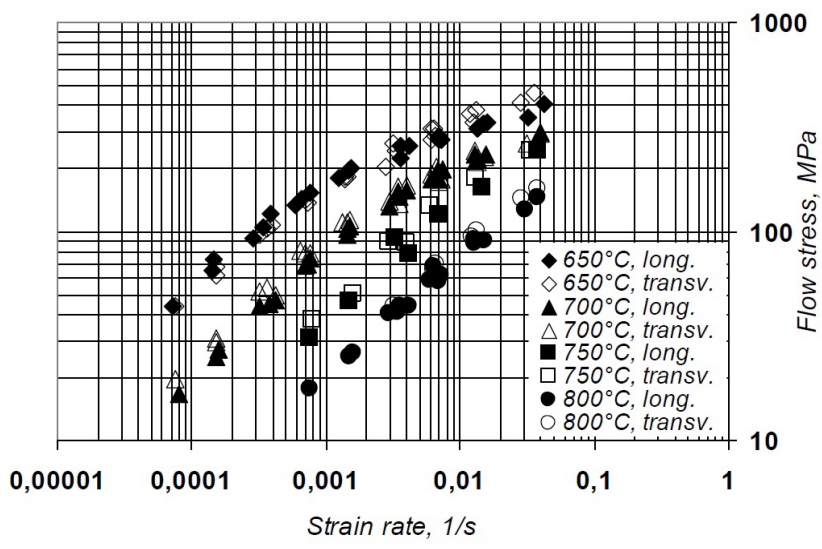

Fig. 7. Variation in the flow stress values of specimens, oriented parallel (longitudinal) and perpendicular (transverse) to the rolling direction of the sheet with a thickness of $1.0 \mathrm{~mm}$, as a function of strain rate at different temperatures.

low-temperature superplasticity in the following deformation conditions:

a) The sheet with a thickness of $1.0 \mathrm{~mm}$ :

at $650^{\circ} \mathrm{C}-700^{\circ} \mathrm{C}$ with a strain rate of $\xi<2 \times 10^{-3} \mathrm{~s}^{-1}$;

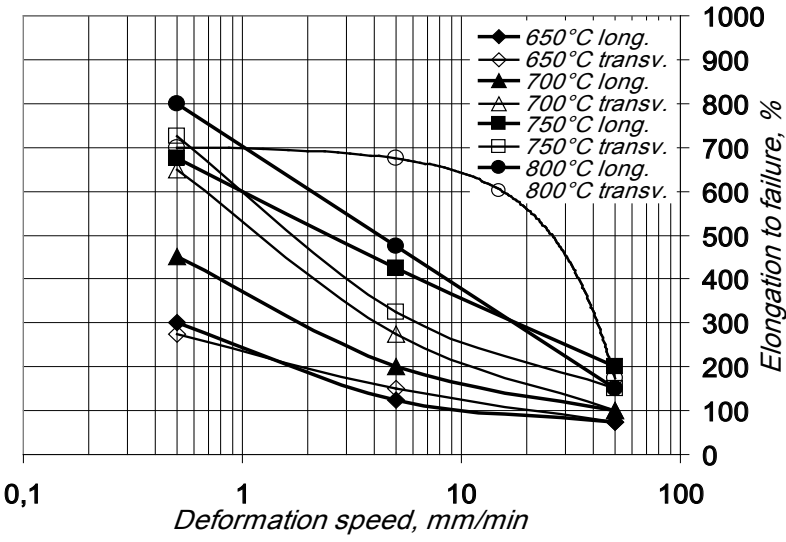

Fig. 4. Variation in the elongation-to-failure values of specimens, oriented parallel (longitudinal) and perpendicular (transverse) to the rolling direction of the sheet with a thickness of $1.5 \mathrm{~mm}$, as a function of deformation speed at different temperatures.

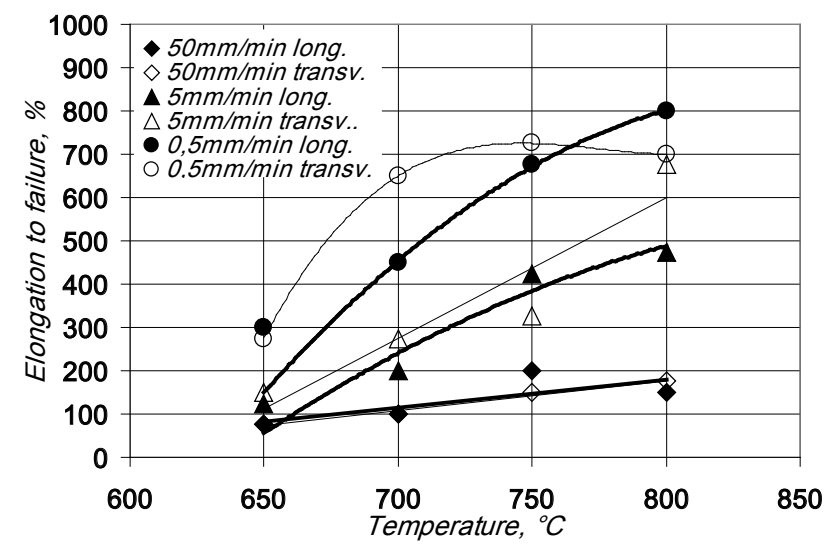

Fig. 6. Variation in the elongation-to-failure values of specimens, oriented parallel (longitudinal) and perpendicular (transverse) to the rolling direction of the sheet with a thickness of $1.5 \mathrm{~mm}$, as a function of temperature at different deformation speeds.

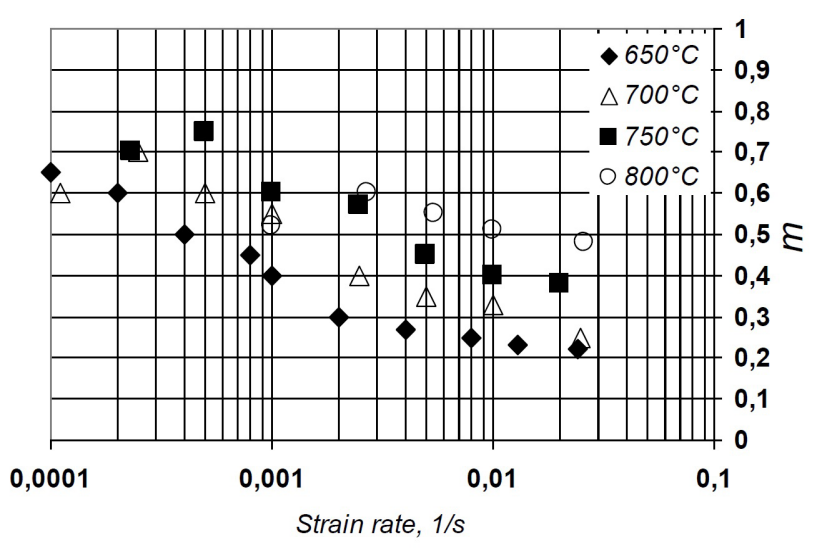

Fig. 8. Variation in the coefficient $m$ values of specimens made from the sheet with a thickness $1.0 \mathrm{~mm}$, with strain rate at different temperatures.

at $700^{\circ} \mathrm{C}-750^{\circ} \mathrm{C}$ with a strain rate of $\xi<1 \times 10^{-2} \mathrm{~s}^{-1}$; at $750^{\circ} \mathrm{C}-800^{\circ} \mathrm{C}$ with a strain rate in the range of $5 \times 10^{-4} \mathrm{~s}^{-1}<\xi<1 \times 10^{-1} \mathrm{~s}^{-1}$.

b) The sheet with a thickness of $1.5 \mathrm{~mm}$ : 


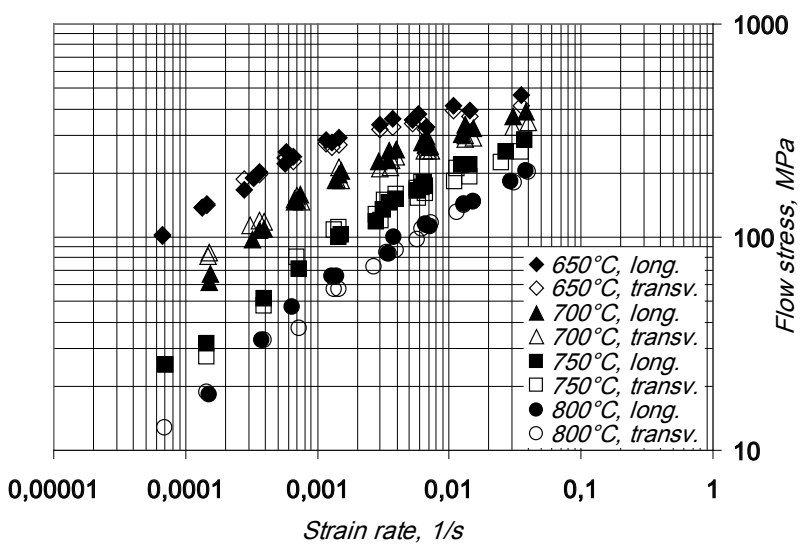

Fig. 9. Variation in the flow stress values of specimens, oriented parallel (longitudinal) and perpendicular (transverse) to the rolling direction of the sheet with a thickness of $1.5 \mathrm{~mm}$, as a function of strain rate at different temperatures.

at $700^{\circ} \mathrm{C}-750^{\circ} \mathrm{C}$ with a strain rate of $\xi<2 \times 10^{-3} \mathrm{~s}^{-1}$; at $750^{\circ} \mathrm{C}-800^{\circ} \mathrm{C}$ with a strain rate of $\xi<1 \times 10^{-2} \mathrm{~s}^{-1}$.

2. All the investigated sheets showed isotropic properties within the scatter of experimental data.

\section{References}

1. E. D. Weisert, G. W. Stacher. Metal Progress. 3, 33 (1977).

2. D. Stephen. The Institute of Metals. London. 9, 108 (1986).

3. O. A. Kaibyshev. Superplasticity of commercial alloys. M., Metallurgiya. (1984) 264 p. (in Russian)

4. European Patent No. 0568201, 1993.

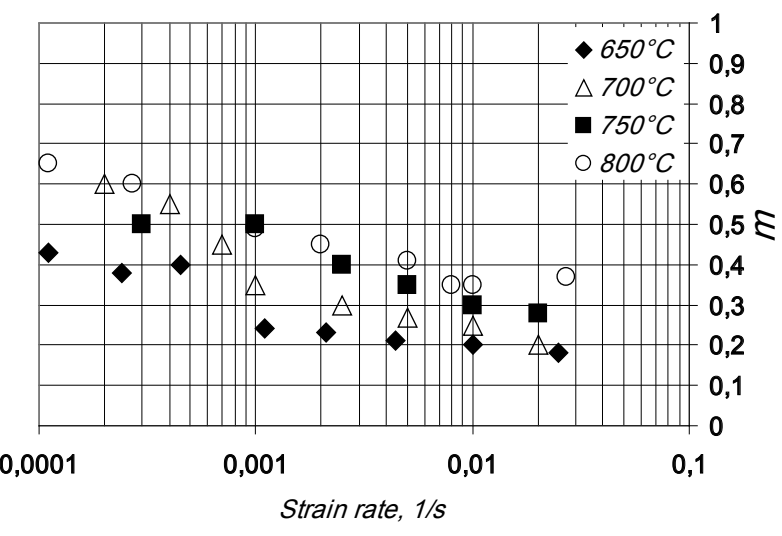

Fig. 10. Variation in the coefficient $m$ values of specimens made from the sheet with a thickness of $1.5 \mathrm{~mm}$, with strain rate at different temperatures.

5. M. W. Turner, I. J. Andrews. Book of Papers. 4th European Conference on Superplastic Forming Euro SPF'05. IOM Communications Ltd. United Kingdom. (2005) p. 39.

6. O.A. Kaibyshev, F.Z. Utyashev. Superplasticity, structure refinement and processing of hard-to-deform alloys. M., Nauka. (2002) 438 p. (in Russian)

7. P. N. Comley. Mater. Sci. Forum. 447-448, 233 (2004).

8. L. D. Hefti. J. of Materials Eng.and Performance. 17, 178 (2008).

9. A. Wisbey, B. Geary, D.P. Davies, C.M. Ward Close Mat. Scien. Forum. 170-172, 293 (1994).

10. O. A. Kaibyshev. Plasticity and superplasticity of metals. M., Metallurgiya. (1975) 280 p. (in Russian) 